\title{
Aspectos positivos e negativos da profissão docente: entre a satisfação e o desejo do professor
}

DOI 10.23864/cpp-v1-n1-66

\author{
Thamiris Christine Mendes \\ Lizie Mendes Clock \\ Ana Lúcia Pereira Baccon
}

\section{Resumo}

Sendo a profissão docente uma imbricação entre as dimensões da vida profissional e da vida pessoal do professor não há como negar as influências que as concepções, representações, crenças e valores do sujeito exercem sobre o ser e constituir-se como docente. O presente artigo apresenta algumas reflexões concernentes a aspectos positivos e negativos da profissão docente, elencados pelos próprios professores, o qual nos permitiu um viés de análise e compreensão sobre a profissão docente voltando-se para a satisfação profissional e o desejo do professor. Trata-se de uma pesquisa qualitativa em que o instrumento de obtenção dos dados empíricos foi um questionário aberto. Constituíram o universo da pesquisa157 docentes atuantes na rede estadual de ensino do Estado do Paraná, pertencem aos Núcleos Regionais de Educação das cidades de Ponta Grossa, Wenceslau Braz e Telêmaco Borba. Em síntese, os resultados demonstraram que os aspectos positivos da docência associam-se com as relações interpessoais vivenciadas no contexto escolar; já os aspectos negativos dizem respeito às características da profissão docente como as condições de organização do trabalho e questões da instituição escolar. A compreensão dos aspectos da profissão docente que correspondem a satisfação e ao desejo do professor são importantes, uma vez que relacionam-se com o ser professor e também com o manter-se na docência.

Palavras-chave: Profissão docente. Satisfação profissional. Desejo. 


\section{Positive and negative aspects of the teaching profession: between satisfaction and teacher's desire}

DOI 10.23864/cpp-v1-n1-66

Thamiris Christine Mendes

Lizie Mendes Clock

Ana Lúcia Pereira Baccon

\section{Abstract}

As the teaching profession is an overlap between the dimensions of professional and personal life of the teacher there is no denying the influence that the citizen's conceptions, representations, beliefs and values have on being and to establish as a teacher. This paper presents some reflections concerning to the positive and negative aspects of the teaching profession, listed by teachers themselves, which allowed us an analytical bias and understanding of the teaching profession turning to job satisfaction and the teacher's desire. It is a qualitative research which instrument of obtaining empirical data was an open questionnaire. It constituted the universe of the research 157 teachers working in the public system of the State Paraná, they belong to Regional Centers of Education of the cities Ponta Grossa, Wenceslau Braz and Telemaco Borba. In summary, the results showed that the positive aspects of teaching are associated with interpersonal relationships experienced in the school context; and the negative aspects relate to the characteristics of the teaching profession such as the conditions of work organization and issues of the school. Understanding the aspects of the teaching profession corresponding to teacher's satisfaction and desire are important because they relate to being a teacher and also to keep in teaching.

Keywords: Teaching profession; Job satisfaction; Desire. 


\section{Introdução}

As mudanças que a pós-modernidade tem provocado na sociedade contemporânea têm afetado diretamente a Educação e o contexto escolar. O professor como agente direto desse contexto sente os efeitos dessas mudanças, tendo que aprender a lidar com variadas situações que vão desde as mais inusitadas, até as mais imprevisíveis.

Toda essa situação de além de ter que aprender com as mudanças do novo tempo, ainda ter que aprender a lidar com o imprevisível, com o inesperado, acaba desencadeando aspectos positivos e negativos na profissão docente, e mexendo com a satisfação e o desejo do professor.

Consideramos que tais aspectos são importantes, uma vez que se relacionam diretamente com o ser professor e também com o manter-se na docência. Além disso, permitenos inferir ainda sobre o desejo do sujeito professor, captados pelo viés da satisfação profissional.

Debruçar-se sobre a profissão do professor é um desafio para os cursos de formação de docentes e para a escola, visto que há uma complexidade em ser professor pelo fato de que este não é só professor, mas desempenha outros papéis na sociedade, ou seja, é também pessoa (NÓVOA, 1995). Isso demonstra que o ser professor é carregado das dimensões pessoais, sociais e profissionais, adquiridos em seu percurso de vida.

A constituição do professor não se constrói por acumulação, se dá mediante sucessivas reconstruções da identidade profissional. A formação do professor avança e recua num contínuo processo de relação com saber e com o conhecimento (NÓVOA, 1995).

Assim, a imbricação entre profissional e pessoal resulta em implicações para o exercício profissional docente na medida em que julgamos que as concepções, representações, crenças e valores pessoais do professor não podem ser desconsiderados na aprendizagem da docência e no ato de ensinar.

Portanto, o propósito da presente pesquisa consiste em desvelar aspectos positivos e negativos da profissão docente evocados pelos professores que participaram da pesquisa. Partimos da premissa que é importante captar os fatores descritos pelos docentes sobre aquilo que identificam como positivo e também como negativo no trabalho que realizam, pois acreditamos que estes são essenciais para compreensão da profissão docente.

Assim esse estudo mostra-se relevante na medida em que proporciona uma compreensão sobre a profissão docente, investigando aspectos positivos e negativos da profissão entre a satisfação e o desejo do professor, que, por sua vez, o fazem permanecer na docência. 


\section{A complexidade do ser professor na contemporaneidade}

A literatura contemporânea traz em seu bojo, estudos que demarcam a influência dos processos de mudança social que transformaram a educação e o papel do professor. $\mathrm{O}$ professor imerso nesse contexto assume inúmeras responsabilidades. Autores como Imbernón (2011), Ens e Donato (2011) e Cosme (2011) corroboram com essa ideia quanto à influência que as constantes transformações da sociedade contemporânea exercem no contexto educacional e consequentemente na função do professor perante a "sociedade do conhecimento" (ENS; DONATO, 2011, p. 87).

As demandas da contemporaneidade caracterizam a sociedade como em tempos de mudanças e incertezas, e nos remetem a uma nova maneira de entender a profissão docente. Há a superação das racionalidades técnicas e práticas que prezam a transmissão de conteúdos, os métodos e técnicas de ensino e a prática docente que permearam a profissão docente durante muito tempo (IMBERNÓN, 2011).

Diante dessa nova configuração que encontramos na sociedade contemporânea é preciso que lancemos um outro olhar sobre a escola e seu papel, aos professores e suas funções, além de um outro posicionamento de todos os envolvidos com a educação, isto porque acreditamos que é importante a valorização da participação dos sujeitos envolvido nesse processo, bem como a sua bagagem sociocultural.

Desse modo, Imbernón (2011, p.12) enfatiza a imprescindível redefinição da docência como profissão, nas palavras do autor "a nova era requer um profissional da educação diferente" e Libâneo (2002) também coloca a importância de pensar e repensar a profissão docente e os processos pelos quais se dão a formação dos professores, visto que, mesmo diante de tantas influências que afetam a educação, a escola ainda "mantém-se como instituição necessária à democratização da sociedade” (LIBANÊO, 2002, p. 3).

Para Cosme (2011) as responsabilidades educativas que os docentes assumem são as que garantem ou não a importância da instituição escolar como insubstituível para a nossa sociedade. [...] "as responsabilidades sociais que dizem respeito às escolas e aos professores são as responsabilidades que decorrem da assunção das suas responsabilidades e compromissos educativos. Nesse sentido, são estas que constituem o núcleo em função do qual se pode interpretar e configurar a atividade docente" (p. 33).

Ainda conforme Cosme (2011) foi pelo viés da instrução que a profissão docente configurou-se como profissão e ganhou espaço socialmente. Entretanto, hoje, não se pode afirmar que o professor é apenas um instrutor. Para a autora, o professor exerce o ato de educar e justifica que a dimensão técnica não é autossuficiente para que o professor exerça sua função, isto por conta de que a modernização de técnicas só acontece a partir de um conjunto de

ISSN 2526-2882

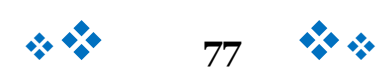


compromissos "de caráter axiológico" por meio dos quais se permite repensar e projetar o ato de educar, isto em função de outras estratégias e dispositivos pedagógicos e didáticos.

Ensinar no contexto escolar é fundamental na sociedade contemporânea. Conforme a fala de docentes e futuros docentes, resgatadas por Tardif e Lessard (2005, p.7), sobre o ensino como profissão que se sobrepõe às outras: "já que o pesquisador, o operário, o tecnólogo, o artista, o político de hoje devem necessariamente ser instruídos antes de ser o que são e para poderem fazer o que fazem".

Para Ens e Donato (2011, p. 83) "A atividade de ensinar realiza-se a partir de conhecimentos específicos e necessários que possibilitam a compreensão do trabalho docente, os quais são adquiridos, construídos na formação inicial e na formação que acontece durante toda a vida profissional”. Ser professor, como explicam Ens e Donato (2011) é:

[...] ser profissional do conhecimento na sociedade do conhecimento, tornouse uma ação complexa e em estado de constante tensão diante dos desafios impostos pela própria profissão de professor e pela sociedade, uma vez que envolve trabalho com e sobre os seres humanos e, por consequência, sofre influências das diversas esferas da sociedade. Tal trabalho é, por sua vez, permeado por teorias e ações práticas que requerem constante reflexão teoriaprática, além da formação continuada. Entende-se que ser professor ante os desafios do novo quadro social, requer nova perspectiva na sua formação (ENS; DONATO, 2011, p. 87).

Para Roldão (2007, p. 94) a função docente caracteriza-se pela ação de ensinar; entretanto, "a função específica de ensinar já não é hoje definível pela simples passagem do saber”. Para a autora mencionada, o conceito de ensinar não é definido de modo simples e fácil, pois há diferença entre "professar um saber" e fazer outras pessoas se apropriarem de um saber/fazer os outros aprenderem alguma coisa. Hoje, o ensino não é concebido como passagem do saber, transmissão de saber, isto porque se tem um acesso alargado às informações.

Para Ens e Donato (2011) o professor, como profissional da educação, coopera qualitativamente para uma mudança da sociedade, mas, para isso, é preciso que haja o compromisso político-social na docência, visto que a formação do cidadão requer uma formação política, e esta, por conseguinte, visa formar cidadão críticos e transformadores. Diante disso, ser professor abrange uma complexa responsabilidade, consiste em formar o aluno, o educando, no intuito de prepará-lo para viver na sociedade das mudanças e incertezas, e para ser capaz de enfrentar desafios.

No entanto, o professor é o profissional da incerteza, do inesperado e diante de tamanho desafio é que questionamos: O que os professores caracterizam como aspectos positivos e como negativos na sua profissão docente? Levando-se em conta as representações sobre o trabalho docente, associando suas experiências enquanto professores e também 
envolve questões peculiares a cada sujeito, como é o caso do desejo docente em ser professor e permanecer na profissão.

Com isso, demarcamos a relevância da profissão docente, e que esta se efetiva nas interações entre professores e alunos, sendo que os saberes precisam ser mediadores dessa relação, caso contrário se configura uma interação interpessoal como outra qualquer. Portanto, a especificidade da docência está em ensinar aos alunos permitindo-lhes que construam um saber, e para isso, é preciso que haja um investimento de energia afetiva do professor (CODO; VASQUEZ-MENEZES, 1999) a fim de mobilizar o discente para o saber (CHARLOT, 2000).

\section{A satisfação profissional e o desejo do sujeito professor}

De acordo com Seco (2000) a atividade docente profissional se orienta também a partir das representações que eles possuem a respeito da sua profissão. De um lado há a ideia da função social que atribuem ao professor, do outro lado tem-se as ações profissionais que desempenham, os quais são orientados pelo conjunto de normas e expectativas estabelecidas pela sociedade e instituições, que por sua vez, são resultantes das representações que possuem da atividade docente.

Desse modo, é possível refletir que a profissão docente possui complexidade e ainda, que a satisfação profissional docente depende também das representações do próprio sujeito e das outras pessoas sobre sua função.

Seco (2000) enfatizou em seu estudo que não há definição unânime quanto à satisfação profissional no trabalho, porém, podemos conceituá-la como um estado positivo vivenciado pelo trabalhador com base no presente e no passado e que recebem influência de fatores contextuais e pessoais (LOCKE, 1976 apud SECO, 2000).

Para Ruivo et al. (2008) existem diversos fatores relacionados à satisfação profissional do professor como elementos da natureza do trabalho, os intrínsecos ao trabalho docente, os quais estão no âmbito do processo de ensino e aprendizagem e outros fatores de cunho afetivo.

Já no que tange à insatisfação dos docentes, Ruivo et. al (2008) citam Barros e Neto (1992) para destacar que encontram-se os fatores conectados ao contexto, à organização e gestão escolar, bem como o clima organizacional, estilo de gestão e às políticas públicas. São estes fatores da insatisfação do professorado nos remetem ao mal-estar docente.

A pesquisa de Ruivo et al. (2008), aconteceu com professores do ensino público de Portugal, do ensino básico e também da educação infantil, que trabalhavam há mais de vinte anos; eram sócios de um sindicato ou associação profissional e detinham uma situação de vinculação estável. O estudo abordou a satisfação profissional do professor e os autores apontaram as seguintes conclusões: os professores sentem-se satisfeitos ao avaliarem sua 
autoestima e autoimagem profissional; a maioria destacou que a sociedade não reconhece seu trabalho, o qual não é proporcional a relação entre o esforço dedicado para exercer suas funções e o reconhecimento; evidenciaram ter capacidade e vontade de serem professores, gostam da profissão, porém, sentem que merecem mais reconhecimento e mais garantias quanto ao futuro profissional. Também expressaram a não satisfação com e interesse dos alunos em aprender e quanto às políticas públicas.

O contexto de insatisfação profissional vem permeando o contexto escolar há algum tempo. Portanto, acreditamos que apresentar algumas reflexões analíticas sobre outros vieses além do campo da Educação pode nos trazer algumas respostas ou apontamento para essas questões. Definimos, então, buscar no campo psicanalítico algumas respostas para esse malestar, para esse "desassossego", para que as queixas dos professores.

Dentro do campo psicanalítico a insatisfação é registrada por meio das queixas do sujeito, no nosso caso, do sujeito professor. Além disso, sob essa ótica a queixa nem sempre está relacionada a uma dor ou a um mal-estar. Na sociedade contemporânea, virou-se hábito se queixar "de tudo", frequentemente: do tempo, do trabalho, das pessoas, da política, da vida, etc. Como profere o psicanalista Jorge Forbes: "a queixa chega a ser a própria pessoa, seu carimbo, sua identidade: "eu sou a minha queixa” (aspas do autor), poderia ser dito" (FORBES, 2003, p.9). O mesmo autor destaca ainda que as pessoas acreditam tanto em suas queixas, em suas lamúrias, que acabam cedendo e emprestam seus corpos para que a doença ali habite, só para comprovar o que dizem e que a "causa primordial de toda queixa é a preguiça de viver" (FORBES, 2003, p.10), pois:

\begin{abstract}
Viver dá trabalho, uma vez que a cada minuto surge um fato novo, uma surpresa, um inesperado que exige correção de rota na vida. Se não for possível passar por cima ou desconhecer o empecilho, menosprezando o acontecimento que perturba a inércia de cada um, surge a queixa, a imediata vontade de culpar alguém, vontade que pode ir aumentando até o ponto em que a pessoa chega a se convencer paranoicamente de que todos estão contra ela, que o mundo não a compreende e que por isso ela é infeliz, pois nada que faz dá certo, enquanto outros, com menos qualidades, obtêm sucesso. Ouvimos, destes, aquele lamento corriqueiro, auto-elogioso: "Acho que sou bom ou boa demais para este mundo, tenho de aprender a ser menos honesto e mais agressivo...”. Conclusão: se não fossem os outros, ele, o queixoso, seria maravilhoso. Por isso, todo queixa é narcísica.
\end{abstract}

Isso nos remete também a situação educacional, em que se trabalha o tempo todo com o imprevisível, com o inesperado. Forbes (2003) destaca ainda que a queixa não surge apenas da dor ou de uma inquietação, mas também como uma forma de proteção, como no caso de quando alguém consegue a realização de um feito, a queixa serve como proteção à inveja dos outros. Ou seja: a culpa da minha queixa é sempre o outro, ou os outros. Sem querer confundir a reivindicação justa com a queixa narcísica, o autor apresenta três pontos de reflexões em que 
a queixa ocorre: a queixa é um fechamento sobre si mesmo; uma recusa da realidade e um desconhecimento da dor real.

$\mathrm{O}$ autor supracitado aponta ainda que um momento fundamental no tratamento psicanalítico é aquele em que o sujeito analisando descobre que não dá mais ficar se queixando, e nesse momento do tratamento descobre-se que "Há que se ajustar à vida, conciliar a palavra com o corpo, fazer da palavra a própria pele até alcançar o almejado sentir-se bem na própria pele" (FORBER, 2003, p. 11).

E no contexto educacional, será que isso é possível? Será que é possível assumir a sua responsabilidade, sem ficar reclamando, sem culpar alguém pelas suas queixas, sejam elas quais forem? Será que o professor consegue sentir satisfação sendo professor ou sentir-se "bem na própria pele"?

Por razões como estas, podemos compreender a satisfação como a realização de algo que se almeja, alcance de plenitude, a realização de um desejo. $\quad \mathrm{O}$ desejo ${ }^{16}$, em uma perspectiva psicanalítica, se define como qualquer forma de movimento direcionado a um objeto de atração; a realização de um anseio, de uma satisfação inconsciente (ROUDINESCO; PLON, 1998).

Chauí (1990) destaca que a palavra desejo deriva-se do verbo desidero que, por sua vez deriva do substantivo sidus (mais usado no plural sidera) relacionando-a com um conjunto de estrelas, constelações, com os astros e suas influências sobre o destino humano. Desiderare, ao contrário encerra o olhar para os astros, tomando a decisão de assumir o próprio destino. Caminha-se em seguida para o termo Desiderium que:

\begin{abstract}
Significa uma perda, privação do saber sobre o destino, queda na roda da fortuna incerta. O desejo chama-se, então, carência, vazio que tende para fora de si em busca de preenchimento, aquilo que os gregos chamavam bormê. Essa ambigüidade do desejo, que pode ser decisão ou carência, transparece quando consultamos os dicionários vernáculos, onde se sucedem os sentimentos de desejar: querer, ter vontade, ambicionar, apetecer, ansiar, anelar, aspirar, cobiçar, atração sexual. A oscilação dos significados aparece na diferença sutil de duas palavras, em português: desejante e desejoso/desejosa (CHAUÍ, 1990, p. 23).
\end{abstract}

Desideriumé o desejo ou apetite de possuir alguma coisa cuja lembrança foi conservada e, ao mesmo tempo, está entravada pela lembrança de outras coisas que excluem a existência da desejada. Chauí (1990) destaca ainda que o "laço que prende o desejo à ausência tornou-se gradativamente a definição do próprio desejo" (p. 24). Dentro dessa perspectiva apresenta ainda uma ideia de desejo segundo Freud, construído a partir da interpretação dos sonhos, em que o pai da psicanálise amarra desejo e memória:

\footnotetext{
${ }^{16}$ Abordamos o desejo em uma perspectiva psicanalítica, entretanto não é nossa intenção adentrar nas questões da metáfora do desejo do analista/desejo do professor (ARRUDA; PASSOS, 2012).
}

ISSN 2526-2882 
Indissociavelmente ligado aos traços da memória, o desejo busca realizar-se pela reprodução alucinatória das percepções antigas nas percepções presente que se tornam, pela via da substituição, sinais precários de sua satisfação. O obscuro objeto do desejo não é, pois, algo real como um objeto natural, mas um sistema de signos que forma o fantasma. Nascido de uma perda irreparável do objeto proibido pela censura (ou pela Lei, instância simbólica), o desejo é a busca indefinidamente repetida dessa perda que não cessa de ser presentificada por outros objetos, sob aspectos aparentemente irreconhecíveis, procurando burlar a censura imposta ao desejante e ao desejado, poder que dispõe graças à potência significante do corpo. Por isso mesmo, o desejo não se confunde com a necessidade ou com o apetite vital, sempre dirigidos a algo presente, desejados a ser suprimidos pelo consumo imediato do que lhes traz satisfação. A relação com a memória é relação com o tempo e o desejo se constitui como temporalidade, aptidão do sujeito para protelar indefinidamente a satisfação, desligando-se do dado presente, encontrando mediações que o remetem ao ausente e abrindo-se para o que conhecemos como imaginário e simbólico (CHAUÍ, 1990, p. 25).

Kupfer (1990, p. 80) destaca que, para Lacan, o desejo está atrelado as noções de demanda e de necessidade, e a necessidade atravessada pela linguagem transforma-se em demanda. A autora enfatiza ainda, que a necessidade está relacionada com um dado biológico, que deve ser satisfeito por um objeto. Já a demanda, é endereçada, dirigida a alguém que possa satisfazê-la. E citando Juranville (1986, p 93), ela destaca que: “A mediação da linguagem é inseparável da mediação do outro [...]. A satisfação de pretensas necessidades pela interveniência do outro a quem se dirige a demanda torna-se, como sublinhou Lacan, sinal do amor. E é ele que é visado na demanda”. Diferentemente da necessidade, como enfatiza Kupfer (1990, p. 81) "aquele que escuta o apelo de uma demanda torna seu demandante digno de se atendido e, portanto, digno de ser amado”.

Seria então, a força que mobiliza o sujeito em busca de satisfação de determinada necessidade, não biológica, mas inconsciente. Sobre isso, Arruda (2001) atenta que não se pode confundir desejo com as necessidades biológicas do corpo, nem com o ‘querer', pois o desejo é uma incessante busca por algo que não está em objetos palpáveis, além de ser incontrolável e não consciente, é não nominável, é uma incógnita.

Quanto mais as demandas aumentam, mais vazio vai se produzindo e este jamais será preenchido, pois como destaca Kupfer (1990, p 82) “[...] aquilo que se pede ao outro é que ele venha a preencher, através de um objeto que supostamente satisfaz, o vazio que se abriu em cada um de nós. O objeto, que supostamente satisfaz, virá com a marca do amor. A falta acima referida é o desejo". Toda demanda está atrelada a um, desejo, mas é “a falta, ou seja, o desejo, que explica o fato de que haja demanda”.

A intenção de buscarmos na Psicanálise algumas contribuições à educação não é com o intuito de que o professor ocupe o lugar do analista, até por que isso não é possível, pois como destaca Kupfer (1990, p. 188): 
[...] embora haja transferência de um aluno para seu professor, este não pode agir como um analista, manejando a transferência como um instrumento de acesso ao inconsciente, pelo simples fato de seu papel não é este, mas tão somente o de ensinar, ou melhor, o de fazer aprender.

A intenção aqui é que o professor ocupe o seu lugar, como sujeito suposto saber, assim como o analista que ajuda o analisando encontrar a sua verdade, o seu saber, o professor como um lugar (BACCON, 2011), invertendo o modelo tradicional de educação, em que o professor ensina falando e o aluno ouvindo, para ensinar ouvindo e aluno aprender falando, possa também levar o aluno ao encontro do conhecimento. Ainda para Kupfer (1990, p.193): “[...] pela via da identificação o professor é colocado pelo aluno no conhecido lugar de modelo que sustenta toda relação pedagógica”.

Esta concepção de ensino que emana da Psicanálise pode atuar como libertadora de algumas normatizações e homogeneização que acontece na Educação. Além disso, para Kupfer (1990, p. 189) o ensino é "um momento privilegiado do aprender de um professor. Também ele, e fundamentalmente ele, o professor, está permanentemente submetido à dialética da sua própria demanda de saber”.

\section{Metodologia}

A pesquisa configura-se em uma perspectiva qualitativa na medida em que se voltou para uma compreensão consistente do objeto de investigação e como forma de apanhar a realidade dos professores pesquisados. Assim sendo, existe inquietação quanto à garantia da riqueza das descrições e a investigação visa apreender o ponto de vista do outro a respeito de como enfrenta as limitações cotidianas (DEZIN; LINCOLN, 2006).

Creswell (2013) define pesquisa qualitativa com o uso de estruturas interpretativas ou teóricas que tem como finalidade informar o estudo dos problemas da pesquisa, abordando os significados que os grupos ou indivíduos atribuem a um problema social ou humano. A pesquisa qualitativa é apropriada ao estudo, por nos fornecer a compreensão complexa e detalhada a respeito da profissão docente.

O estudo se concretizou no ano de 2013 com 157 docentes da rede estadual de ensino do Paraná, os quais pertencem aos Núcleos Regionais de Educação das cidades de Ponta Grossa, Wenceslau Braz e Telêmaco Borba. Os sujeitos, na maioria são mulheres (78,12\%), que por sua vez, possuem entre 34 e 61 anos de idade, sendo que a bagagem de experiência profissional oscila de 9 a 33 anos de prática.

Com intenção de identificar quais os aspectos descritos pelos professores como positivos e negativos da profissão docente, utilizamos como instrumento de coleta dos dados 
um questionário com perguntas abertas e direcionadas à identificação dos aspectos que caracterizam os docentes a permanecer na profissão.

Após a coleta das informações da pesquisa, as mesmas foram submetidas ao processo de análise textual discursiva, considerado por Moraes e Galiazzi (2011) como ferramenta analítica que permite aos pesquisadores produzir compreensão e significado acerca do fenômeno investigado. Trata-se de um movimento constante de interpretação das informações para a produção de sentido e significado.

Os professores participantes da presente pesquisa foram levados a elencar alguns aspectos positivos e alguns negativos da profissão docente. Neste momento dedicamos esforços para analisar os aspectos evocados em primeiro lugar, tanto positivos como negativos. Para preservar a identidade dos sujeitos de pesquisa, os mesmos serão representados pela letra $\mathrm{P}$ acompanhada de um número, que representa a ordem na organização dos questionários. Assim sendo, P1 representa o primeiro professor participante, P2 o segundo e assim sucessivamente.

\section{Interpretando os aspectos positivos da profissão docente}

No que se refere aos aspectos positivos da profissão do professor obtivemos, a partir do processo de análise textual discursiva (MORAES; GALIAZZI, 2011), duas categorias, as quais são exploradas a seguir.

\section{Categoria I - O professor como pessoa}

Esta categoria abrange um grupo de respostas dos professores em que observamos que os aspectos positivos da profissão docente, em sua maioria (54,14\%), as respostas voltam-se para: as relações interpessoais vivenciadas na escola; o reconhecimento do que faz pelo outro e a possibilidade de transformar a sociedade.

a) As relações interpessoais vivenciadas na escola: Notamos que para estes docentes os aspectos positivos da profissão do professor se associam predominantemente com o fato de ser uma profissão que envolve contato constante com as pessoas, exige interações, como colocaram alguns dos pesquisados P2, P31, P54, P78 e P99: "convívio humano", "interação com alunos", "proximidade com pessoas", "oportunidade de interação com o outro" e "relacionamento com pessoas".

Podemos inferir, nesta categoria que, retomando as colocações de Seco (2000) ao enfatizar que a atividade docente é orientada pelas representações que o sujeito tem da 
profissão, da função social inerente a ela, o que, influi ainda na satisfação profissional no trabalho.

Sendo o professor uma imbricação entre aquilo que é de ordem da vida pessoal e também da vida profissional (NÓVOA, 1995), podemos inferir que para os professores pesquisados, os aspectos positivos da profissão docente se fazem principalmente nas relações interpessoais construídas no contexto de trabalho. Assim, a satisfação docente se manifesta nesta relação e é influenciada por ela, bem como podemos afirmar que há um desejo do sujeito professor de estar envolvido com os diferentes atores educacionais.

Pensando sob o viés da Psicanálise podemos destacar que "as relações interpessoais vivenciadas na escola" evidenciadas na categoria I: "O professor como pessoa" de certa forma também podem ser relacionadas com o que Chauí (1990) chama de relação com a memória, “é relação com o tempo e o desejo se constitui como temporalidade, aptidão do sujeito para protelar indefinidamente a satisfação, desligando-se do dado presente, encontrando mediações que o remetem ao ausente e abrindo-se para o que conhecemos como imaginário e simbólico" (CHAUÍ, 1990, p. 25). Como se percebe com os dados, é por meio do "convívio humano", da "interação com alunos", da "proximidade com pessoas", da "oportunidade de interação com o outro" e do "relacionamento com pessoas" que os sujeito pesquisados demonstram satisfação com a docência.

b) O reconhecimento do que faz pelo outro: Observamos que a profissão do professor, de acordo com os sujeitos da pesquisa, tem como aspecto positivo o reconhecimento, ou seja, é gratificante quando as outras pessoas reconhecem o trabalho que o professor realizou como relataram P18, P29, P38, P48, P61 e P123: "respeitado por muitos", "reconhecimento dos alunos e pais", "reconhecimento", "buscar reconhecimento", "reconhecimento por parte dos alunos" e "todos te conhecem" e alguns também disseram que é gratificante.

Inferimos a partir de nossos dados que a satisfação do professor está relacionada com o reconhecimento de outras pessoas e de si mesmo de seu trabalho, daquilo que ele faz, dos resultados, do produto que se faz quando atua como professor. Nesse caso, poderíamos pensar que é quando o aluno aprende, mas, nem sempre o professor volta-se para isso. Os docentes satisfazem-se quando alguém percebe/reconhece qualquer atitude dele, não só com o aprendizado, como foi constatado pela pesquisa de Mendes (2015). Para a autora, um dos fatores que contribuem para que o docente mantenha-se na profissão, mesmo diante de muitas dificuldades, desgaste emocional e condições de trabalho, é o reconhecimento, uma das principais motivações da atuação do professorado.

Vale ressaltar que esse reconhecimento está relacionado com o desejo em ser percebido pelo outro, desejo em ser visto, considerando-se a definição de desejo de Chauí (1990) como busca por aquilo que falta, a carência que tem em si e busca preenchê-la no seu exterior. 
Ou podemos denominar isso de demanda, como destaca Kupfer (1990), pois toda demanda está atrelada a um desejo, mas é "a falta, ou seja, o desejo, que explica o fato de que haja demanda" e esta é endereçada, dirigida a alguém que possa satisfazê-la, no caso do professor, essa demanda pode ser preenchida pelo aluno.

c) A possibilidade de transformar a sociedade: De acordo com alguns dos participantes da pesquisa o aspecto positivo da profissão docente está no fato de permitir a mudança nas pessoas, em suas vidas, e na sociedade e do professor como formador de opinião, conforme ilustra-se com as falas de P4, P8, P34, P55, P58, P92: "transformação do ser humano", "formador de opinião", "contribui para a formação de pessoas", "tem o poder de direcionar e mudar a sociedade", "ser capaz de orientar pessoas para influenciar suas vidas positivamente", "conseguir resgatar alguns alunos dados como perdidos".

Esta categoria demonstrou que, para os próprios docentes, a profissão do professor se associa com algo que está além do processo de ensino e aprendizagem. Dito de outro modo, a docência tem de positivo o fato de oportunizar ao professor que ele contribua para um projeto maior de educação, que não se restringe ao ensinamento de conteúdos das disciplinas que lecionam.

Autores como Ens e Donato (2011) confirmam que o professor pode promover mudanças na sociedade, desde que tenha compromisso político-social ao exercer a docência. É através do compromisso social que se torna possível a formação de cidadãos críticos, e para isso, é necessário também uma formação política que objetiva a constituição de criticidade e sujeitos transformadores.

Para que tal compromisso se estabeleça se exige formação e preparação dos professores para atuarem na sociedade das mudanças e incertezas, e para serem capazes de enfrentar os diversos desafios impostos (IMBERNÓN, 2011).

De modo geral, os fatores positivos da profissão docente descritos pelos sujeitos da pesquisa se referem ao envolvimento do professor com pessoas, seja nas relações que vivencia na escola, seja na espera pelo reconhecimento daquilo que fez/faz pelo outro, ou ainda na possibilidade de gerar transformações na sociedade, por meio do seu trabalho. São elementos que remetem à dimensão do professor enquanto pessoa e que manifestam a satisfação profissional docente relacionada ao outro.

Para Roudinesco e Plon (1998) desejo é aquilo que mobiliza o sujeito em busca da realização de uma necessidade inconsciente. Com isso, inferimos a partir das respostas que nos permitiram organizar esta categoria, que o desejo do professor se direciona em ser percebido pelos outros, em ajudar as pessoas e contribuir para um mundo melhor, não se resumindo em ensinar conteúdos aos discentes. 
Conforme destaca Kupfer (1990), o desejo, para Lacan, se relaciona com noções de necessidade transformada em demanda do sujeito endereçada a alguém ou objeto que possa satisfazê-la. Portanto, pode-se inferir que, sobre os aspectos positivos da profissão docente, citados pelos pesquisados, compreende-se que a satisfação do desejo docente acontece ainda quando ele se reconhece como sujeito que, por meio de seu trabalho, da relevância social atribuída a ele, tem a possibilidade de causar mudanças na sociedade. Ou seja, é alguém "especial”, que tem poder.

Sobre a possibilidade de transformação inerente à representação da atividade docente, Mendes (2015) revelou que é um dos fatores mais importantes do ser e do manter-se professor.

A categoria demonstrou que os docentes associam a profissão docente como algo que está além do processo de ensino e aprendizagem. O professor é considerado como mobilizador das potencialidades dos sujeitos a serem educados, e os alunos fazem parte de um projeto maior de educação, que não se restringe apenas a aprendizagem de conteúdos. A docência tem como aspecto positivo oportunizar a possibilidade de transformação da sociedade.

\section{Categoria II - O professor no processo de ensino e aprendizagem}

Já os aspectos positivos citados pelos docentes enquadrados nesta categoria, a qual atingiu um percentual de 35,03\% das respostas, percebemos que são os aspectos que permeiam o processo de ensino e aprendizagem como: "o crescimento pedagógico do aluno" (P1), "ensinar" (P24; P25). Ou seja, relacionam-se à aprendizagem discente, também ao prazer em ensinar, além de ligarem-se ainda ao fato de estarem envolvidos com os conhecimentos, de aprender quando ensinam, ao aprendizado próprio como observamos com P35, P44, P96: "estar sempre aprendendo", "participar do processo de construção do conhecimento", "poder transmitir conhecimentos”. O restante das respostas apresentadas 10,82\% não se enquadrou nas categorias encontradas.

Conforme Ens e Donato (2011) ser professor é ser um profissional do conhecimento, o que não é tão simples na sociedade contemporânea. Compreendendo que a função do docente é a de ensinar conhecimentos específicos (ROLDÃO, 2007), implicando no envolvimento com o processo de ensino e aprendizagem, nos deparamos com algo que nos chamou a atenção: se cabe ao docente ensinar aos alunos, por que os aspectos positivos da profissão docente citados pelos sujeitos pesquisados enfatizam em primeiro lugar o prazer em relacionar-se com as pessoas, o reconhecimento do outro daquilo que o professor faz e a possibilidade de transformar a sociedade?

Pensando nisso, retomamos a questão do desejo. Interpretamos que o desejo do professor ultrapassa a efetivação do processo de ensino e aprendizagem. Os docentes participantes da pesquisa demonstraram desejo de ir além da sala de aula, de poder causar mudanças na sociedade e na qualidade de vida dos alunos. 
Desse modo, a satisfação profissional docente, quando analisados os aspectos descritos como positivos da profissão do professor, está em superar a aprendizagem dos alunos contribuindo para uma formação crítica e política discente.

Levando em conta que Ruivo et. al. (2008) esclareceu que são diversos os fatores que influenciam na satisfação profissional (natureza do trabalho, intrínsecos ao trabalho, de cunho afetivo), os professores da presente pesquisa demonstram a satisfação mais influenciada por fatores afetivos e relacionais do que os intrínsecos ao trabalho, como o ensino e aprendizagem. Podemos inferir a partir disso que ser professor supera a questão meramente de escolha profissional. Há algo a mais na busca por ser professor, o que se relaciona com o desejo do sujeito para suprir uma falta inscrita na sua psique, uma demanda (CHAUí, 1990).

A segunda categoria nos mostra, em suma, os aspectos positivos da profissão docente, ligados ao papel do professor como parte integrante do processo de ensino e aprendizagem. $\mathrm{O}$ professor demonstra sua satisfação profissional quando supera a concepção de transmissão de conhecimentos, e contribui para uma formação crítica e política dos educandos. A satisfação profissional reside, inclusive, em promover mudanças sociais qualitativas na vida dos alunos.

\section{Interpretando os aspectos negativos da profissão docente}

Para a classificação dos aspectos positivos citados pelos sujeitos pesquisados conseguimos organizar os dados e construir duas categorias. No entanto, o mesmo não ocorreu com os aspectos negativos, pois conseguimos identificar apenas uma categoria e outras duas que denominamos como "vertentes" por conta de sua baixa frequência. Vejamos:

\section{Categoria A - Condições de trabalho/aspectos organizacionais}

A categoria que alcançou 68,15\% das respostas dos professores abrange os aspectos negativos da profissão docente como: "baixa valorização" (P2); "sobrecarga" (P3), "pouco reconhecimento" (P5), “acúmulo de funções” (P9), “falta de estrutura” (P13), "falta de material didático e espaço" (P29), "falta de tempo" (P59), "turmas com muitos alunos" (P78). Notamos que estes aspectos encontram-se relacionados com questões pertinentes às condições de trabalho que os professores possuem e à valorização da profissão por meio de salário e também pelo reconhecimento daquilo que faz.

Conforme explicaram Ruivo et al. (2008), a insatisfação profissional geralmente é relacionada com fatores da organização do trabalho, do contexto, como, por exemplo o clima organizacional, o estilo da gestão e às políticas, o que confirma-se nesta pesquisa. Sendo que estes aspectos citados são ainda atrelados ao mal-estar que se faz na profissão docente, que por sua vez, manifesta-se nas queixas docentes. 
Ainda Ruivo et al. (2008) apontaram, com sua investigação, que a insatisfação dos professores está na falta de reconhecimento do seu trabalho e também ao considerarem que o esforço que desempenham na profissão não tem relação de igualdade com o reconhecimento social da sua atividade. Isso é comprovado na presente pesquisa ao desvendarmos os aspectos positivos citados pelos docentes da pesquisa, os quais, quando não atendidos, revertem-se em aspectos negativos da profissão demarcando a não satisfação do desejo. Assim, corrobora-se com os autores supracitados confirmando os fatores de insatisfação relacionados à dimensão organizacional da profissão docente.

Encontramos outras duas vertentes de respostas dentro desta categoria. Entretanto, como a frequência das respostas nas vertentes B e C são relativamente baixas optamos em analisar apenas a categoria A. Trata-se de subitens porque se associam a categoria maior, ligada aos fatores que influem nas condições de trabalho:

Vertente B - Indisciplina discente: Com 18,47\%, abrange os aspectos negativos da profissão docente que elencamos como relacionados aos alunos, à indisciplina, o desrespeito em sala de aula.

Não podemos deixar de destacar aqui que essa vertente da "indisciplina discente" também pode fazer para das "queixas" do professor, pois como destaca Forbes (2003) a queixa não surge apenas da dor ou de uma inquietação, mas também como uma forma de proteção, ou ainda: a culpa da minha queixa é sempre o outro, ou os outros. Como diria o autor, sem querer confundir a reivindicação justa com a queixa narcísica, não podemos nos esquecer dos três pontos de reflexões em que a queixa ocorre: a queixa é um fechamento sobre si mesmo; uma recusa da realidade e um desconhecimento da dor real. Então, no caso dos sujeitos aqui pesquisados, pode sim ser responsabilidade dos alunos, mas ao mesmo tempo, tais aspectos podem também fazer parte das queixas dos professores pesquisados.

Vertente C - Desgaste do professor: Embora tenha atingido percentual de $9,55 \%$ esta classificação envolve os aspectos que se referem ao desgaste do professor, físico e mental. Referem-se aos impactos psicológicos que a profissão exerce sobre o sujeito. O sujeito é acometido por desgaste profissional, que interfere diretamente em seu profissionalismo, e consequentemente no desempenho de sua função.

O desgaste profissional se manifesta pelas queixas, mas como vimos que assim como no tratamento psicanalítico o momento fundamental é aquele em que o sujeito analisando descobre que não dá mais ficar se queixando, e que é nesse momento do tratamento que ele descobre-se que "Há que se ajustar à vida, conciliar a palavra com o corpo, fazer da palavra a própria pele até alcançar o almejado sentir-se bem na própria pele” (FORBES, 2003, p. 11). Ou seja, que é necessário assumir a sua responsabilidade, sem ficar reclamando, sem culpar 
alguém pelas suas queixas, e sentir satisfação sendo professor e agir com profissionalismo que como destaca Cavagnari e Papi (2005) refere-se ao comprometimento ao exercício profissional, no qual o professor precisa ser competente, trabalhar de forma colaborativa, buscar formação continuada, ser responsável por suas ações profissionais e perceber fatores internos e externos que influenciam.

Observando a categorização tanto dos aspectos negativos como dos positivos descritos pelos docentes sobre a profissão do professor notamos que as respostas dos sujeitos foram mais convergentes no que tange aos elementos negativos, o que constituiu apenas uma categoria de análise. Já sobre os aspectos positivos, as respostas foram mais divergentes, gerando duas categorias de análise. Diante disso, refletimos que ambos os aspectos são dependentes das experiências e da subjetividade de cada sujeito professor, além de também refletir as representações construídas histórica e socialmente, porém, por que houve mais "convergência” dos professores nos aspectos negativos? Demonstraram mais convicção nesses aspectos, mais facilidade. Em contrapartida, os fatores positivos variaram muito, o que nos permitiu inferir que o positivo está atrelado mais ao desejo do sujeito professor do que os negativos.

\section{Considerações preliminares}

Embora existam idiossincrasias pertencentes a cada professor, consideramos que os dados contém revelações importantes sobre a profissão docente. Vale ressaltar que "a preocupação central não é a de se os resultados são susceptíveis de generalização, mas a de que outros contextos e sujeitos a eles possam ser generalizados" (BOGDAN; BIKLEN, 1994, p.66).

Os dados obtidos por meio desta investigação, bem como as reflexões suscitadas por estes no que se refere à profissão docente revelaram, em resumo, que para os docentes os aspectos positivos da docência associam-se com as relações interpessoais vivenciadas no contexto escolar. Já os aspectos negativos dizem respeito às características da profissão docente como as condições de organização do trabalho e questões da instituição escolar.

Analisando os aspectos citados pelos professores como positivos e negativos concluímos que a atividade docente está diretamente relacionada com a satisfação e o desejo do sujeito professor. A investigação relacionada com a profissão docente ainda nos permitiu inferir os aspectos positivos que colaboram para que o professor continue na profissão, e os aspectos negativos que geram "mal-estar" profissional.

Os aspectos positivos corroboram com a ideia da profissão docente centrada na figura do professor. O professor permanece na docência, principalmente devido às relações interpessoais vivenciadas na escola, especialmente as interações sociais. Também pelo 
reconhecimento do outro, no sentido da satisfação que as pessoas vislumbram pelo seu trabalho. Inclusive, pela possibilidade de transformar o ambiente em que vivem - educação como um compromisso social. Por fim, é elencado o processo de ensino e aprendizagem, em que os professores valorizam sua participação na construção do conhecimento, tornando-se também fator decisivo para manter-se na profissão.

Os aspectos negativos circulam menos nas questões pessoais do professor e materializam-se nas condições de trabalho e nos aspectos organizacionais que influenciam diretamente no estabelecimento da profissão docente. As vertentes associam-se a valorização da profissão, à indisciplina dos alunos e a situação emocional do próprio professor.

A pesquisa mostrou a relevância em se conhecer os aspectos que fazem o professor manter-se ou "queixar-se" da profissão, uma vez que a partir disso é possível inferir em questões pontuais que colaborem para a valorização docente.

A temática dos aspectos que permeiam a profissão docente apresenta importância para a compreensão do ser professor, além disso, atrela-se à satisfação profissional do professor e ao desejo do sujeito em ser e manter-se na docência, logo, é digna de melhor exploração em outras pesquisas.

\section{Referências}

ARRUDA, S. de M. Entre a inércia e a busca: reflexões sobre a formação em serviço de professores de física do ensino médio. Tese de Doutorado. FEUSP. São Paulo, 230p., 2001.

ARRUDA, S. de M.; PASSOS, M. M. Da psicanálise ao ensino de ciências: o desejo do docente e o professor como um lugar. Ciência e Educação (Bauru), v. 18, n. 1, 2012, p. 6980.

BACCON, A. L. P. O professor como um lugar: um modelo para análise da regência de classe. Curitiba: Honoris Causa, 2011.

BOGDAN, R.; BIKLEN, S. Investigação qualitativa em Educação: uma introdução à teoria e aos métodos. Portugal: Porto Editora, 1994.

CAVAGNARI, L. B. PAPI, S. de O. G. Trabalho docente, espaço institucional e contexto social. Ponta Grossa: UEPG/CEFORTEC, 2005.

CHARLOT, B. Da relação com o saber: elementos para uma teoria. Porto Alegre: Artmed, 2000. 93p.

CHAUÍ, M. Laços do Desejo. In: . O Desejo. São Paulo: Companhia das Letras, 1990. p. $19-66$. 
CODO, W.; VASQUES-MENEZES, I. O que é Burnout? In: CODO, W. (Org.). Educação: carinho e trabalho. Petrópolis: Vozes, 1999. p. 237-254.

COSME, A. Ser professor numa escola e num tempo de incertezas. In: ENS, R. T.; BEHRENS, M. A. (Orgs.). Ser professor: formação e os desafios na docência. Curitiba: Champagnat, 2011. p. 27-53.

CRESWELL, J. W. Investigação qualitativa e projeto de pesquisa: escolhendo entre cinco abordagens. 3. ed. Porto Alegre, RS: Penso, 2014.

DENZIN, N. K.; LINCOLN, Y. S. Introdução: a disciplina e a prática da pesquisa qualitativa. In: O planejamento da pesquisa qualitativa: teorias e abordagens. 2. ed. Porto Alegre: Artmed, 2006. p. 15-41.

ENS, R. T.; DONATO, S. P. Ser professor e formar professores: tensões e incertezas contemporâneas. In: ENS, R. T.; BEHRENS, M. A. (Orgs.). Ser professor: formação e os desafios na docência. Curitiba: Champagnat, 2011. p. 79-100.

FORBES, J. Você quer o que deseja? São Paulo: Best Seller, 2003.

IMBERNÓN, F. Formação docente e profissional: forma-se para a mudança e a incerteza. 9. ed. v. 14. São Paulo: Cortez, 2011.

KUPFER, M. C. O desejo de saber. Tese de Doutorado, Instituto de Psicologia, Universidade de São Paulo, São Paulo, 1990.

LIBÂNEO, J. C. Adeus professor, Adeus professora? Novas exigências educacionais e profissão docente. São Paulo: Cortez, 2002. 104p. ISBN: 85249-0678-2.

MENDES, T. C. Profissional docente: o ser e o manter-se na docência. Dissertação (Mestrado em Educação) - Universidade Estadual de Ponta Grossa, Programa de PósGraduação em Educação, 2015.

MORAES, R.; GALIAZZI, M. do C. Análise textual discursiva. 2. ed. Ijuí: Ed. Unijuí, 2011. NÓVOA, A. Formação de professores e profissão docente. In: Os professores e sua formação. 2. ed. Lisboa: Dom Quixote, 1995. p. 13-33.

ROLDÃO, M. do C. Função docente: natureza e construção do conhecimento profissional. Revista Brasileira de Educação, v. 12, n. 34, jan./abr., 2007. p. 94-181.

ROUDINESCO, E.; PLON, M. Dicionário de psicanálise. Rio de Janeiro: Jorge Zchard, 1998.

RUIVO, J. et al.Ser Professor: satisfação profissional e papel das organizações de docentes. Editorial IPCB, 2008.

SECO, G. M. B. dos S. A satisfação na actividade docente. Faculdade de Psicologia e de Ciências da Educação. Tese de Doutorado. 492p. Universidade de Coimbra, Coimbra, 2000.

TARDIF, M.; LESSARD, C. O trabalho docente: elementos para uma teoria da docência como profissão de interações humanas. Petrópolis: Vozes, 2005. 


\section{Biografia Resumida}

Thamiris Christine Mendes - Mestre (2015) em Educação pela Universidade Estadual de Ponta Grossa (UEPG) e doutoranda pelo mesmo programa. Psicóloga e Pedagoga. Professora Colaboradora do Departamento de Pedagogia (DEPED) da UEGP. Integrante do projeto de pesquisa "Políticas Educacionais e Formação de Professores" (UEPG).

Currículo Lattes: http://lattes.cnpq.br/6595545609888079

Contato: mendesthamirisc@hotmail.com

Lizie Mendes Clock - Mestre em Educação pelo Programa de PósGraduação em Educação da Universidade Estadual de Ponta Grossa, na linha de pesquisa de Ensino e Aprendizagem (2014 2016). Licenciada em Pedagogia pela Universidade Estadual de Ponta Grossa (2013). Integrante do projeto de pesquisa "Políticas Educacionais e Formação de Professores" (UEPG).

Currículo Lattes: http://lattes.cnpq.br/7716300792500034 Contato: lizieclock@hotmail.com

Ana Lúcia Pereira Baccon - Doutora (2011) e Mestre (2005) em Ensino de Ciências e Educação Matemática pela Universidade Estadual de Londrina (UEL). Especialista em Educação Matemática pela Universidade Estadual do Norte do Paraná UENP (1996). Possui graduação em Ciências e Matemática pela Universidade Estadual do Norte do Paraná UENP (1994). Professor Adjunto na Universidade Estadual de Ponta Grossa no Departamento de Matemática e Estatística e no Programa de Pós-Graduação em Educação (Mestrado e Doutorado) na UEPG (desde 2012). Professora de Matemática na Rede Pública no Estado do Paraná (1994-2012). Cargos exercidos: Vice-coordenadora do Programa de Pós-Graduação em Educação (Mestrado e Doutorado) na UEPG (Universidade Estadual de Ponta Grossa 2014/2015). Coordenação Institucional do PIBID/UEPG 2012/2013. Coordenadora de Gestão e Processos Educacionais PIBID/UEPG desde 2013. Chefe do Núcleo Regional de Educação de Jacarezinho (2009-2010). Presidente da APP- Sindicato dos Trabalhadores em Educação 
Núcleo Regional de Jacarezinho (2002-2009). Atualmente é líder do Grupo de Pesquisa GEPPE (Grupo de Estudo e Pesquisa Políticas Educacionais e Formação de Professores). Membro do corpo editorial (Editor Associado) de Frontiers in Educational Psychology. Desenvolve pesquisas nas seguintes linhas: Políticas Educacionais e Formação de professores; Desenvolvimento curricular e práticas pedagógicas; Ensino e aprendizagem; Psicanálise e Educação Matemática.

Currículo Lattes: http://lattes.cnpq.br/4341211442617752 Contato: ana.baccon@hotmail.com 


\title{
Formação continuada para o ensino de MATEMÁTICA: Um estudo em Vilhena ${ }^{17}$
}

DOI: $10.23864 / c p p-v 1-n 1-45$

\author{
Maria Candida Müller
}

Joélice Pederiva Barbosa

Juracy Machado Pacífico

\section{Resumo}

O artigo apresenta a pesquisa realizada com professoras dos Anos Iniciais do município de Vilhena - RO que participaram de atividades de formação continuada propostas pelo projeto GETEMAT - Grupo de Estudo e Trabalho Pedagógico do Ensino de Matemática ${ }^{18}$. O objetivo foi analisar como as professoras consideraram as ações desenvolvidas durante sua participação o Projeto GETEMAT para a mudança de sua prática pedagógica. A partir de uma abordagem qualitativa, foram utilizados como instrumentos de coleta de dados: diário de campo das reuniões, relatos das professoras sobre as reuniões através de um memorial, e entrevista semiestruturada. O referencial teórico estudado privilegiou os autores da área de formação de docentes e Educação Matemática. Durante a coleta de dados foi possível testemunhar quão importante foi para os professores e professoras participarem de uma formação continuada através de um grupo de estudo, pois tiveram a oportunidade de questionar, expor suas dúvidas e angústias e, com o diálogo com os demais participantes, vivenciaram trocas de experiências e saberes que possivelmente irão refletir na sua prática em sala de aula.

Palavras-Chave. Formação inicial. Formação continuada. Ensino de matemática. Pesquisa-ação.

\footnotetext{
${ }^{17}$ Artigo elaborado a partir de uma monografia apresentada como requisito parcial de avaliação no curso de graduação em Pedagogia/2012, orientada pela terceira autora.

${ }_{18}$ Projeto de Pesquisa Financiado pelo CNPq Edital n ${ }^{0} 55 / 2008-C T$ Amazônia.
}

ISSN 2526-2882

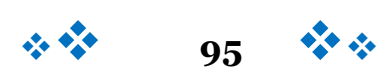




\title{
Continuing education the teaching of Mathematics: a study in Vilhena
}

\author{
Maria Candida Müller \\ Joélice Pederiva Barbosa \\ Juracy Machado Pacífico
}

\section{Abstract}

This paper presents a study of a group of teachers who attended a continuing education proposed by the project GETEMAT - Study Group and Educational Work of the Teaching of Mathematics. Aimed to analyze how the teachers of the early years of the public schools of Vilhena considered Project GETEMAT to change their practice. From a qualitative approach, were used as instruments of data collection: field diary of meetings, reports from teachers about the meetings, and semi-structured interview. The theoretical study authors focused in the area of teacher formation and and teaching mathematics. It was observed how important is for teachers participated in a continuing education through a study group, as well they had the opportunity to ask questions, express their doubts and fears and, in dialogue with others participant experiencing exchanged experiences and knowledge that will be reflected in practice in the classroom.

Keywords. Initial formation. Continuing education. Math education. Action research. 


\section{Primeiras ideias}

Há muitos estudos sobre formação continuada de professores (IMBERNÓN, 2009; NACARATO; MENGALI; PASSOS, 2009; CURI, 2005; BORBA, 2006), mas na prática não se percebe resultados significativos de mudança de postura pedagógica do professor.

Silva (2002) demonstra que uma formação continuada que traz resultado é aquela que ocorre dentro da própria escola, através de grupos de estudo, no qual os professores atuam e têm a oportunidade de refletir sobre suas práticas e juntos solucionarem os problemas de aprendizagem dos alunos. Este autor critica a formação continuada oferecida nos programas governamentais, nos quais os professores são meros ouvintes, nem ao menos são questionados sobre suas ideias e práticas, desenvolvendo uma temática específica dos conteúdos escolares ou sobre metodologias, sem considerar $\theta$-os professores realmente necessitam conhecer para repensar sua prática pedagógica.

Especificamente, com relação ao ensino de Matemática, percebe-se através dos resultados das pesquisas realizadas pelo antigo Saeb (Sistema de avaliação da educação básica) e atual Prova Brasil 2005 e 2007, as dificuldades que os alunos têm em relação a esta disciplina, sinal que também os professores não estão conseguindo proporcionar aos estudantes uma aprendizagem que resulte no entendimento dos conceitos trabalhados pela escola. Uma das formas de se reverter o quadro com relação ao desempenho dos alunos em Matemática possivelmente será com a formação continuada dos professores dos anos iniciais do ensino fundamental para o ensino desta disciplina.

As propostas de formação continuada geralmente propõem atualizações de conteúdos específicos e/ou metodologias de ensino que possibilitem a reflexão sobre a prática docente e possibilitem mudanças no processo de ensinar e aprender na educação básica. No entanto, a formação continuada em serviço professor possivelmente só terá resultado quando o próprio docente assumir um papel ativo neste processo, propondo discussões que efetivamente possibilitem uma reflexão sobre seu trabalho pedagógico e traga como consequência a descoberta de outras maneiras de ensinar e aprender, que acompanhem o desenvolvimento de teorias e estudos atuais sobre como se dá o processo ensino-aprendizagem dos discentes.

Assim, a pesquisa desenvolvida ao longo de três anos pelo Projeto GETEMAT (AUTOR, 2009, 2011) buscou dados que corroborassem a perspectiva de formação docente baseada na constituição de grupos de estudo colaborativo e cooperativo congregando docentes da educação básica dos anos iniciais, docentes da universidade e futuros professores e professores, estudantes do curso de Pedagogia.

Os dados apresentados neste artigo correspondem a um dos objetivos do Projeto GETEMAT que era avaliar junto aos docentes que participaram dos encontros do grupo a

ISSN 2526-2882

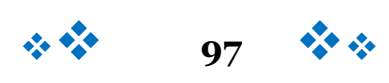

